\title{
Should We Start with an Easy Task Having a Short Deadline, or a Difficult Task Having a Long Deadline
}

\author{
Miki Adachi ${ }^{*}$, Keisuke Adachi² \\ ${ }^{1}$ Osaka Electro-Communication University, Neyagawa, Osaka, Japan \\ ${ }^{2}$ Kobe Gakuin University, Kobe, Hyogo, Japan \\ Email: ^m-terada@osakac.ac.jp
}

How to cite this paper: Adachi, M., \& Adachi, K. (2021). Should We Start with an Easy Task Having a Short Deadline, or a Difficult Task Having a Long Deadline. Psychology, 12, 1878-1885.

https://doi.org/10.4236/psych.2021.1211113

Received: October 7, 2021

Accepted: November 27, 2021

Published: November 30, 202

Copyright $\odot 2021$ by author(s) and Scientific Research Publishing Inc. This work is licensed under the Creative Commons Attribution International License (CC BY 4.0).

http://creativecommons.org/licenses/by/4.0/

\section{(c) (i) Open Access}

\begin{abstract}
Prior studies have investigated people's task-order decisions, whether people put off a task or start the task as soon as possible. However, the effect of the time frame, whether the task has a long or a short deadline, on task order decisions has not been clarified. We hypothesized that 1) starting a series of tasks with a difficult task when given a long deadline is related to increased self-control; 2) starting with an easy task given a long deadline is related to reduced self-control and starting with an easy task given a short deadline enhances well-being and self-control. A cross-sectional study $(N=1085,21$ - 78 years age) supported these hypotheses. These findings are extended current knowledge by identifying differences in the time frame and expected to clarify how people make task order decisions.
\end{abstract}

\section{Keywords}

Task Order, Procrastination, Pre-Crastination, Self-Control

\section{Introduction}

There is a close relationship between a task order and an individual's benefits. For example, when processing multitasks at work, the order in which you start tasks leads to slimming of work and an efficient working style. Depending on the task order in which a businessperson's work is done, procrastination can sometimes occur, which can lead to stress and reduced productivity. Zhu, Yang, and Hsee (2018) showed from five experiments demonstrate that people want to finish the urgent tasks involved more immediate first and then work on important tasks later (the mere urgency effect). Procrastination also occurs because of 
this.

Procrastination is defined as the tendency to put off or postpone tasks that should be addressed (Lay, 1986). The irrational procrastination of a task that we know must be completed leads to some maladaptive outcomes. Prior studies have revealed that procrastination interferes with academic performance (Klassen, Krawchuk, \& Rajani, 2008; Ljubin-Golub, Petričević, \& Rovan, 2019). Academic procrastination is also considered avoiding fears of failure and anxiety (Schouwenburg, 1992), associated with negative emotions such as anxiety, depression, and low self-confidence (Lay \& Silverman, 1996). Moreover, students with high metacognitive skills such as time management, planning, and monitoring skills necessary for academic work are less likely to procrastinate (Lay \& Schouwenburg, 1993; Wolters, 2003; Zhao, Meng, Sun, Xu, Geng, \& Han, 2019).

On the other hand, pre-crastination is defined as "the tendency to complete or at least begin, tasks as soon as possible, even at the expense of extra physical effort" (Rosenbaum, Gong, \& Potts, 2014; Vonder Haar, McBride, \& Rosenbaum, 2019). Pre-crastination has recently been revealed as an analogous tendency to the mere-urgency effect. Pre-crastination is related to minimizing the anticipated fear and pain of negative/adverse tasks (Harris, 2012), the desire to reduce cognitive load, and the preference for completing more cognitively demanding tasks early (VonderHaar et al., 2019). Adachi and Adachi (2021a) demonstrated that assignments were submitted faster by students who considered the assignments as adverse. Simultaneously, completing a disliked task first can increase the expectations and benefits of a favorite task that is expected to be completed later (Rosenbaum \& Sauerberger, 2019).

Completing a task sooner, even at the expense of extra physical effort, might be a form of self-control when there is a long deadline (Baumeister, Tice, \& Vohs, 2018). Steel (2007) showed that strong correlations between procrastination and impulsiveness, a lack of self-control. People must have patience and concentration to suppress other temptations and start a series of tasks with a difficult task. Therefore, people who start with a difficult task might have more self-control. We predicted that people who start a series of tasks with a difficult task and procrastinate less would have worked faster on homework assignments during summer vacations. In Japanese schools, there is a long vacation in summer for students. The timing of embarking on their homework assigned during these rare long vacations is an indicator of their procrastination tendencies. We ask participants to recall when they did their assigned homework during summer vacations in childhood.

Is it also the case that people who start a series of tasks with an easy task have reduced self-control? Habbert and Schroeder (2020) examined the benefit of starting a series of tasks with a difficult task by focusing on self-efficacy. Their findings indicate that self-efficacy is maximized when people start a series of tasks with the most difficult task rather than the easiest tasks. However, it has also been demonstrated that ordering exam questions from easy to hard questions produces significantly more optimistic performance evaluations (Weins- 
tein \& Roediger, 2010). Also, people that eat a favorite food immediately experience more positive feelings than people who eat a favorite food later (Adachi \& Adachi, 2021b). It would be worthwhile examining individual benefits of eating by considering the eating order as one factor enhancing individual benefits. The common denominator in testing and eating is the short deadline for completing the task. Starting with an easy task given a short deadline has an enhancing effect on the individual's well-being, possibly resulting in less procrastination. On the contrary, when given a long deadline, starting with an easy task might cause procrastination, and they might put off homework during summer vacations.

\section{The Present Study}

The purpose of this study was to examine the relationship between the task order and self-control under two different timeframes. More specifically, we tested whether 1) people who start a series of tasks with a difficult task procrastinate less and had quickly completed their homework during summer vacations; 2) people who start a series of tasks with an easy task given a long deadline procrastinate more and had put off homework during summer vacations; people who start a series of tasks with an easy task given a short deadline enhance their well-being, making them less likely to procrastinate. We conducted a cross-sectional survey focusing on the task order, procrastination, and homework timing as a measure of self-control.

\section{Method}

\subsection{Participants}

An internet survey was conducted by a pooling company (Fastask). The participants were adults, randomly selected from monitors registered in Fastask, who responded to a questionnaire package. The responses of monitors without missing values were analyzed. The data of 1085 participants (546 men and 539 women, age: $\mathrm{M}=44.94$ years, $\mathrm{SD}=14.00$, Range $=21-78)$ were collected. None of the respondents were excluded.

\subsection{Measures}

\subsubsection{Procrastination}

We used the 13-item General Procrastination Scale (Hayashi, 2007). Participants were asked to rate the extent to which each item applied to them on a 5-point scale ranging from 1 (Does not apply) to 5 (Applies). The higher is the score on this scale; the higher is procrastination. We used mean scores in the analysis ( $\alpha=$ $0.85, \mathrm{M}=2.73, \mathrm{SD}=0.61$.

\subsubsection{Timing of Embarking Homework in Summer Vacations}

Participants were asked the question, "when you were a child, how soon did you usually do your homework during vacations?" They were told to choose one item that applied to them from the following items: 1) I did it at the beginning of the vacation; 2) I did it more or less at the beginning of the vacation; 3) I did it 
nearly evenly every day; 4) I did it more or less at the end of the vacation; 5) I $\mathrm{did}$ it at the end of the vacation. We used the mean scores of the responses $(\mathrm{M}=$ $2.91, \mathrm{SD}=1.33)$ in the analysis.

\subsubsection{Task-Order}

First, participants were asked to choose a sentence that best described their behavior when they are faced with a task or an assignment with a long deadline from the following choices: 1) I am the type of person that starts with the easy task; or 2) I am the type of person that starts with the difficult task. There were 733 people reporting that they started with the easy task and 352 people reporting that they started with the difficult task.

Next, we asked the respondents to indicate whether they ate their favorite food immediately or later. Given a short deadline, 518 people reported eating their favorite food first, and 567 reported eating their favorite food later.

\subsection{Design}

An independent samples t-test compared scores for 1) procrastination and 2) the timing of starting homework in the two groups (respectively, start with an easy task or a difficult task with a long or a short deadline). The free statistical software package, HAD (Shimizu, 2016), was used for the analysis.

\section{Results}

\subsection{Descriptive Statistics}

As shown in Table 1, the task order given a long deadline was negatively correlated with procrastination and the time of starting homework. In contrast, the task order given a short deadline correlated with the time of starting homework.

\subsection{Effect of Task-Order on Procrastination and Timing of Starting Homework}

Comparing procrastination scores between people starting a series of tasks with an easy or a difficult task when given a long deadline indicated significant between-group differences. People that started a series of tasks with an easy task had significantly higher procrastination scores than those that started with a difficult task, indicating that people who started a series of tasks with an easy task procrastinated more than people who started with a difficult task. However,

Table 1. Correlation.

\begin{tabular}{llcccccc}
\hline & & 1 & & 2 & & 3 \\
\hline 1 & procrastination & - & & & & & \\
2 & timing of embarking homework & 0.271 & $* *$ & - & & & \\
3 & task-order in a long deadline & -0.147 & $* *$ & -0.102 & $* *$ & - & \\
4 & task-order in a short deadline & 0.013 & & 0.084 & $* *$ & 0.296 & $* *$ \\
\hline
\end{tabular}

Note: ${ }^{\star \star}$ means $p<0.01$. 
there were no significant group differences in procrastination between people who started a series of tasks with an easy or a difficult task when given a short deadline.

Comparing scores for the time of starting homework between people who started a series of tasks with an easy or a difficult task when given a long deadline indicated significant differences. People that started with an easy task given a long deadline started their homework later than those who started with a difficult task. In contrast, people that started with an easy task given a short deadline also started their homework earlier than people who started with a difficult task. We propose that starting a series of tasks with a difficult task is related to having more self-control, whereas starting with an easy task is related to a reduced self-control only when given a long deadline. Also, people starting with an easy task and a short deadline started their homework earlier, although it did not affect procrastination (Table 2).

\section{Discussion}

People regularly make task order decisions on whether to put off a task or start a task as soon as possible. This study increased our understanding of the task order decision process by examining the relationship between the task order classified by short or long deadlines and self-control, defined as procrastinating or starting homework early during summer vacations.

We found that starting with a difficult task was associated with self-control because people suppressed their immediate impulses to enjoy later. Our findings align with previous studies indicating that procrastination is related to a failure of self-regulation (Baumeister et al., 2018; Ramzi \& Saed, 2019; Steel, 2007). We also found that people who started with an easy task had low self-control, but it is noteworthy that those who started with an easy task did not necessarily fail at self-control, but rather, they were able to exercise self-control in eating situations with a short deadline. These findings extend our understanding by clarifying differences in the task order of conducting general tasks (with a long deadline) and the order of eating meals (with a short deadline).

Table 2. Result of t-test.

\begin{tabular}{|c|c|c|c|c|c|c|}
\hline & $\mathrm{M}(\mathrm{SD})$ & $\mathrm{M}(\mathrm{SD})$ & $t$-value (df) & $d$ & & $\mathrm{CI}$ \\
\hline \multirow{2}{*}{ procrastination } & $\begin{array}{l}\text { start with easy (short) } \\
\qquad 2.73(0.57)\end{array}$ & $\begin{array}{l}\text { start with difficult (short) } \\
2.74(0.64)\end{array}$ & $0.42(1083)$ & 0.02 & -0.14 & 0.09 \\
\hline & $\begin{array}{l}\text { start with easy (long) } \\
2.8(0.59)\end{array}$ & $\begin{array}{l}\text { start with difficult (long) } \\
2.61(0.63)\end{array}$ & $4.88(1083)^{\star \star}$ & 0.31 & 0.18 & 0.44 \\
\hline \multirow{2}{*}{$\begin{array}{l}\text { timing of embarking } \\
\text { homework }\end{array}$} & $\begin{array}{l}\text { start with easy (short) } \\
2.80(1.29)\end{array}$ & $\begin{array}{c}\text { start with difficult (short) } \\
3.02(1.37)\end{array}$ & $2.77(1083)^{\star \star}$ & -0.16 & -0.28 & -0.05 \\
\hline & $\begin{array}{c}\text { start with easy (long) } \\
3.01(1.31)\end{array}$ & $\begin{array}{l}\text { start with difficult (long) } \\
2.72(1.36)\end{array}$ & $3.37(1083)^{\star *}$ & 0.21 & 0.09 & 0.34 \\
\hline
\end{tabular}

Note: ${ }^{\star \star}$ means $p<0.01$. 
Starting with the easy task (the mere urgency effect; Zhu et al., 2018) is a disadvantage, in that it leads to procrastination. Various interventions have been cited to improve procrastination, which is a failure of self-control (Rozental \& Carlbring, 2014). For example, there are behavioral/cognitive interventions, such as setting specific goals (Locke \& Latham, 2002) and scheduling (Wolters, 2003), setting specific locations and routines (McCrea, Liberman, Trope, \& Sherman, 2008), modifying irrational beliefs about time management and efficacy in accomplishments, and setting incentives and peer pressure. This study revealed new findings the effectiveness of starting with easy when the task has a short deadline. It seems that provide immediate gratification may lead to optimistic procrastination, but which may work if the deadline is short-term.

Prior studies have not clarified the length of the deadline in task order decisions. This study's findings are expected to facilitate more efficient ordering in the future by considering the available time frame for completing the task. Previous studies have demonstrated that participants with the shortest reaction time had the strongest tendency to pre-crastinate, and participants with the longest reaction time had the strongest tendency to procrastinate (Blinch \& DeWinne, 2019), suggesting the influence of the time frame in task order "decisions". Short-term tasks such as exams and eating are routine, and many of their characteristics are habitual and automatic. Short-term self-control failures in the task order, such as eating a favorite food first, might be related to optimism and have adaptive effects (Adachi \& Adachi, 2021b). It can be explained explicitly that procrastination and pre-crastination in terms of self-control from two perspectives: long-term and short-term.

The childhood family environment might also influence the timing of starting homework during summer vacations. It is suggested that future research should focus on the following points, based on the above discussion. First, this finding may be due to future studies should experimentally investigate. Second, these results must be further investigated in a longitudinal study.

In conclusion, the results of this study indicate the perspective relationship between the more efficacy task-order and individual's benefit and highlighted that 1) starting with a difficult task is related to having more self-control, whereas, 2) starting with an easy task is related to a reduced self-control only when given a long deadline. Also, 3) people starting with an easy task and a short deadline started their homework earlier. These findings extend our understanding by clarifying differences in the task order of conducting general tasks (with a long deadline) and the order of eating meals (with a short deadline).

\section{Conflicts of Interest}

The authors declare that there is no conflict of interest.

\section{References}

Adachi, M., \& Adachi, K. (2021a). Correlation between Class Evaluation of University Stu- 
dents and Procrastination. Journal of Educational and Developmental Psychology, 11, 70-75. http://doi.org/10.5539/jedp.v11n2p70

Adachi, M., \& Adachi, K. (2021b). Personality Factors Determine the Attitudes toward Eating Behavior. International Journal of Psychological Studies, 13, 38-43. https://doi.org/10.5539/ijps.v13n3p38

Baumeister, R. F., Tice, D. M., \& Vohs, K. D. (2018). The Strength Model of Self-Regulation: Conclusions from the Second Decade of Willpower Research. Perspectives on Psychological Science, 13, 141-145. https://doi.org/10.1177/1745691617716946

Blinch, J., \& DeWinne, C. R. (2019). Pre-Crastination and Procrastination Effects Occur in a Reach-to-Grasp Task. Experimental Brain Research, 237, 1129-1139. https://doi.org/10.1007/s00221-019-05493-3

Habbert, R., \& Schroeder, J. (2020). To Build Efficacy, Eat the Frog First: People Misunderstand How the Difficulty-Ordering of Tasks Influences Efficacy. Journal of Experimental Social Psychology, 91, Article ID: 104032. https://doi.org/10.1016/j.jesp.2020.104032

Harris, C. R. (2012). Feelings of Dread and Intertemporal Choice. Journal of Behavioral Decision Making, 25, 13-28. https://doi.org/10.1002/bdm.709

Hayashi, J. (2007). Development of Japanese Version of General Procrastination Scale. The Japanese Journal of Personality, 15, 246-248. https://doi.org/10.2132/personality.15.246

Klassen, R. M., Krawchuk, L. L., \& Rajani, S. (2008). Academic Procrastination of Undergraduates: Low Self-Efficacy to Self-Regulate Predicts Higher Levels of Procrastination. Contemporary Educational Psychology, 33, 915-931. https://doi.org/10.1016/j.cedpsych.2007. 07.001

Lay, C. H. (1986). At Last, My Research Article on Procrastination. Journal of Research in Personality, 20, 474-495. https://doi.org/10.1016/0092-6566(86)90127-3

Lay, C. H., \& Schouwenburg, H. C. (1993). Trait Procrastination, Time Management. Journal of Social Behavior and Personality, 8, 647-662.

Lay, C., \& Silverman, S. (1996). Trait Procrastination, Anxiety, and Dilatory Behavior. Personality and Individual Differences, 21, 61-67. https://doi.org/10.1016/0191-8869(96)00038-4

Ljubin-Golub, T., Petričević, E., \& Rovan, D. (2019). The Role of Personality in Motivational Regulation and Academic Procrastination. Educational Psychology, 39, 550-568. https://doi.org/10.1080/01443410.2018.1537479

Locke, E., \& Latham, G. (2002). Building a Practically Useful Theory of Goal Setting and Motivation. American Psychologist, 57, 705-717. https://doi.org/10.1037/0003-066X.57.9.705

Ramzi, F., \& Saed, O. (2019). The Roles of Self-Regulation and Self-Control in Procrastination. Psychology and Behavioral Science International Journal, 13, Article ID: 555863. https://doi.org/10.19080/PBSIJ.2019.13.555863

Rosenbaum, D. A., Gong, L., \& Potts, C. A. (2014). Pre-Crastination: Hastening Subgoal Completion at the Expense of Extra Physical Effort. Psychological Science, 25, 1487-1496. https://doi.org/10.1177/0956797614532657

Rosenbaum, D. A., \& Sauerberger, K. S. (2019). End-State Comfort Meets Pre-Crastination. Psychological Research, 83, 205-215. https://doi.org/10.1007/s00426-018-01142-6

Rozental, A., \& Carlbring, P. (2014). Understanding and Treating Procrastination: A Review of a Common Self-Regulatory Failure. Psychology, 5, 1488-1502.

https://doi.org/10.4236/psych.2014.513160 
McCrea, S. M., Liberman, N., Trope, Y., \& Sherman, S. J. (2008). Construal Level and Procrastination. Psychological Science, 19, 1308-1314. https://doi.org/10.1111/j.1467-9280.2008.02240.x

Schouwenburg, H. C. (1992). Procrastinators and Fear of Failure: An Exploration of Reasons for Procrastination. European Journal of Personality, 6, 225-236. https://doi.org/10.1002/per.2410060305

Shimizu, H. (2016). An Introduction to the Statistical Free Software HAD: Suggestions to Improve Teaching, Learning and Practice Data Analysis. Journal of Media, Information and Communication, 1, 59-73.

Steel, P. (2007). The Nature of Procrastination: A Meta-Analytic and Theoretical Review of Quintessential Self-Regulatory Failure. Psychological Bulletin, 133, 65-94. https://doi.org/10.1037/0033-2909.133.1.65

VonderHaar, R. L., McBride, D. M., \& Rosenbaum, D. A. (2019). Task Order Choices in Cognitive and Perceptual-Motor Tasks: The Cognitive-Load-Reduction (CLEAR) Hypothesis. Attention, Perception, \& Psychophysics, 81, 2517-2525.

https://doi.org/10.3758/s13414-019-01754-Z

Weinstein, Y., \& Roediger, H, L. (2010). Retrospective Bias in Test Performance: Providing Easy Items at the Beginning of a Test Makes Students Believe They Did Better on it. Memory \& Cognition, 38, 366-376.

https://doi.org/10.3758/MC.38.3.366

Wolters, C. A. (2003). Understanding Procrastination from a Self-Regulated Learning Perspective. Journal of Educational Psychology, 95, 179-187.

https://doi.org/10.1037/0022-0663.95.1.179

Zhao, J., Meng, G., Sun, Y., Xu, Y., Geng, J., \& Han, L. (2019). The Relationship between Self-Control and Procrastination Based on the Self-Regulation Theory Perspective: The Moderated Mediation Model. Current Psychology, 40, 5076-5086.

https://doi.org/10.1007/s12144-019-00442-3

Zhu, M., Yang, Y., \& Hsee, C. K. (2018). The Mere Urgency Effect. Journal of Consumer Research, 45, 673-690. https://doi.org/10.1093/jcr/ucy008 